\title{
OVERCOMING ERRORS: A CLOSER LOOK AT THE ATTRIBUTIONAL MECHANISM
}

\author{
Gert J. Homsma \\ Cathy Van Dyck \\ Dick De Gilder \\ Paul L. Koopman \\ Tom Elfring \\ VU University
}

\begin{abstract}
We extend the knowledge about the causal attribution mechanism by investigating the roles of causal ascription (stability and locus of causality) and causal interpretation (personal control and responsibility) after error occurrence. One hundred twenty-five participants were randomly assigned to one of four experimental conditions (internal vs. external by unstable vs. stable attribution instructions). Internal unstable ascriptions lead to higher perceived control after error occurrence. Both control and responsibility, in turn, predict task behavior. While causal interpretation predicts outcome measures, causal ascriptions are related to the same measures only indirectly. Implications for research and practice are discussed.
\end{abstract}

KEY WORDS: error occurrence; causal attribution; functional task behavior.

\section{INTRODUCTION}

"Errors are always forgivable if one has the power to acknowledge them." (De La Rochefoucauld, 1815, p. 86). With this aphorism, the French author may have pointed out the impact of the construal of meaning after causes have been assigned to errors. People identify such causes, as it is functional to obtain knowledge about events, for example

Address correspondence to Gert J. Homsma, Department of Work and Organizational Psychology, Faculty of Psychology, VU University, Van der Boechorststraat 1, 1081 BT, Amsterdam, The Netherlands. E-mail: gj.homsma@psy.vu.nl 
for the purpose of undertaking subsequent action (Kelley, 1971). Assigned causes can lead to considerable differences in behavior (Weiner, 1985, 1986). It has been shown that causes like lack of effort are more desirable than others (e.g., lack of ability), as they lead to constructive (e.g., determination) rather than destructive (e.g., learned helplessness) behavior (Anderson, 1983; Dweck, 1975; Försterling, 1985; Medway \& Venino, 1982; Weiner, 1986).

In error management training, behavior after error occurrence is influenced by the presentation of positive error heuristics like "I have made an error. Great!" (Heimbeck, Frese, Sonnentag, \& Keith, 2003). These positive error heuristics are presented to facilitate emotional coping after error occurrence, thereby aiding people to consider that errors can also be interpreted as informative feedback (Heimbeck et al., 2003). It has been shown that error management training leads to more functional task behavior such as more requests for assistance, less frustration and better performance than does error avoidant training (Chillarege, Nordstrom, \& Williams, 2003; Nordstrom, Wendland, \& Williams, 1998).

People thus engage in functional behavior when they interpret error occurrence as a situation from which positive aspects can appear. Although restraining negative emotional reactions after error occurrence leads to functional, performance oriented interpretations of error, it is not clear how the process of interpretation after error occurrence leads to functional task behavior. Our goal is therefore to establish the influence of causal attribution on behavior after error occurrence, based on three literatures of success and failure attribution (theory of motivation and emotion, Weiner, 1985; self-efficacy theory, Bandura, 1982; theory of learned helplessness, Abramson, Seligman, \& Teasdale, 1978). We propose, furthermore, a new way of studying the causal attribution mechanism. We decided not to use explicit causes such as lack of effort for the manipulation of the causal attribution dimensions as recent research has shown that explicit causes do not lead to equivalent outcomes on the causal attribution dimensions (Van Dyck \& Homsma, 2005). We will first found our proposition that causal assignment after error occurrence influences subsequent behavior. Next, we will describe in detail the new way of studying the causal attribution mechanism.

\section{Attribution after Error Occurrence}

Behavior after error occurrence is related to performance. Edmondson (1996) found that teams that were more open about errors, had a more constructive error handling approach and better performance than groups that were less open about errors. Functional behavior after 
error occurrence is optimized by means of early error detection, quick and effective correction and error analysis (Van Dyck, 2000). Although behavior after error occurrence is associated with performance, little is known about the origin of those behaviors. Weiner's $(1985,1986)$ attributional model of motivation and emotion has identified causal attributions as important predictors of behavior. The causes that people perceive (e.g., after making errors) can be classified among three common dimensions: locus of causality, stability, and controllability, with intentionality and globality as possible other dimensions (Weiner, 1985). Heider (1958) proposed the most fundamental dimension: locus of control. Causes can be attributed to factors within the person (internal locus) or to factors that lie within the environment (external locus). Weiner et al. (1971) later redefined this causal dimension into locus of causality, thereby differentiating the dimension locus (of control) from perceived control. They further reasoned that some causes are perceived as constant whilst other causes are perceived as unstable, and proposed a second dimension of causality: stability. A cause, apart from being internal or external, is defined as stable when it remains constant, and as unstable when it is likely to fluctuate. Rosenbaum (1972) proposed the dimension controllability by recognizing that causes like effort, mood and fatigue all are considered to be internal, unstable causes, but differ in the extent to which control can be exerted over them. That is, mood and fatigue are causes that are to a lesser degree under control than effort expenditure. Although it is beyond dispute that controllability plays an important role in giving meaning to situations, there has been some debate about the incorporation of this third dimension control in the 2 (locus of causality) $\times 2$ (Stability) classification (e.g., Hewstone \& Antaki, 1988).

A major complication of the attributional model is that the three dimensions, although conceptually distinct, are also highly interrelated (e.g., Anderson, 1983). As a result, some combinations of the 2 (Locus of causality) $\times 2$ (Stability) $\times 2$ (Control) classification that Weiner (1985) proposed, seem contradictory. As Weiner (1986, pp. 49-50) noted, "external-controllable and stable-controllable causes are difficult to imagine." For example, if a striker in a soccer match assigns a missed scoring opportunity to the poor condition of the soccer pitch (assignment to an external locus), there is little room for the striker to gain control over the situation. In the same vein, stable-controllable attributions are difficult to imagine. When for example, the striker attributes a missed goal scoring opportunity to a lack of ability (assignment to stable cause), there is again little room for the striker to gain a certain amount of control over the situation. In the remainder of the introduction it is discussed how we have dealt with this contradiction, by proposing a new way to study the causal attribution mechanism. 


\section{Causal Ascriptions and Behavior}

As causal attributions have big impact on subsequent behavior, several theories have described the influence of causal attributions. Research has shown that internal unstable ascriptions after failure generally lead to more functional behavior than the other types of ascriptions (Abramson et al., 1978; Bandura, 1982; Weiner, 1985). Weiner (1985) proposed that unstable causal ascriptions after failure lead to constructive behavior as the expectancy to perform those tasks successfully remains unaffected. That is, if the cause of an outcome is seen as unstable, the cause that led to the negative outcome is not necessarily expected to occur again and, therefore, the expectancy to perform well on that task would remain unaffected. If, on the other hand, a cause of an outcome is considered as stable, the cause is expected to reoccur when working on the same task, and thereby lowers the expectancy to perform well on that task.

Following Bandura (1977), desirable causes for failure are low effort or bad luck because those explicit causes should lead to desirable attributions (internal and external unstable respectively), which maintain the belief in one's capabilities to organize and execute the sources of action required to manage prospective situations.

In Seligman's theory of learned helplessness (Abramson et al., 1978; Maier \& Seligman, 1976) it is suggested that situations can be perceived as generally controllable or uncontrollable, which lead to feelings of determination or feelings of learned helplessness. Attributing outcomes to controllable causes such as effort, an internal unstable attribution, would then lead to an active task approach. Attributing outcomes to uncontrollable situations such as lack of ability, in contrast, would lead to the undesirable causes of learned helplessness (Dweck, 1975).

It has thus been argued that the dimensions of causal attribution, locus of causality, stability and controllability predict desirable and undesirable behavior after failure. Internal unstable and internal controllable causal ascriptions after failure should lead to functional task behaviors such as persistence, an active approach towards achievement tasks and unimpaired performance. On the other hand, stable, stable internal, and uncontrollable causal attributions after failure lead to less functional task behavior such as lower persistence and effort expenditure. The key question, however, is whether the influence of attributional style on behavior after failure situations is similar to the influence of attributional style on behavior when people make errors.

To our knowledge, only one study has explored attributional style in relation to error handling behavior. Van Dyck (2005) found that internal, controllable attributions after error occurrence led to better performance. When participants acknowledged responsibility for an error and made 
control oriented suggestions for improvement in future tasks, control, learning and performance were enhanced. This finding is in line with the attribution literature as well as with research on attributional retraining (for an overview, see Försterling, 1985). If people attribute failure to their own lack of effort (an internal and unstable cause), this is likely to lead to an active task oriented approach (Dweck, 1975). It has been shown that such desirable causes also lead to functional task behaviors such as high persistence and accuracy (e.g., Chapin \& Dyck, 1976; Fowler \& Peterson, 1981; Schunk, 1981). Concerning the relation between causal ascription and behavior after error occurrence, we expect that:

Hypothesis 1: Internal unstable causal ascription of error leads to more functional task behavior than the other types of causal ascription.

In the current study we use an alternative approach to study the relations between causal ascription and functional task behavior. In the majority of studies investigating the influence of the dimensions of causal attribution on behavior, explicit causes such as lack of effort have been used for the manipulation of locus of causality and stability (e.g., internal and unstable; Weiner, 1985). We decided not to use explicit causes for the manipulation of locus of causality and stability as recent research has shown that explicit causes do not lead to equivalent outcomes on the dimensions of causal attribution (Van Dyck \& Homsma, 2005). Van Dyck and Homsma showed that people may ascribe and even agree upon explicit causes, but do not have to take action that is in line with this explicit cause. People might agree upon explicit causes for events such as lack of effort when performing a certain task, but do not necessarily have to make an internal and unstable ascription for that explicit cause. Van Dyck and Homsma studied participants who were presented with tasks for which too little time was offered. Time pressure was indeed recognized by almost all participants (93\%) as the primary cause. This explicit cause, however, yielded striking differences on the causal attribution dimensions. With the cause time pressure in mind, some ascribed the locus internally whilst others made external ascriptions. There may, thus, be a difference between the assignment of an explicit cause and the ascription to causal attribution dimensions. Explicit causes may therefore be less appropriate for the manipulation of causal attribution dimensions.

Although it has been shown quite convincingly that explicit causes like lack of effort are more desirable than other explicit causes (Weiner, $1980,1985)$, it is not clear whether the causal attribution mechanism is sufficiently explained by the causal dimensions of locus of causality and stability. A second disadvantage of using explicit causes for the manipulation of explicit causes namely is that they also automatically involve a 
certain amount of causal interpretation. An explicit cause such as lack of effort, for example, is meant to bring forth an internal and unstable ascription. This internal and unstable ascription would then lead to subsequent functional task behavior. Another plausible possibility is that instead of an internal and unstable ascription, this explicit cause can bring forth an interpretation of being capable to pursue that same task successfully in the future; the perception of personal control. By using explicit causes for the manipulation of ascription, it is thus not clear whether causal ascriptions (e.g., internal and unstable) or interpretational processes (e.g., perceived control) affect behavior. For example, if the explicit cause lack of effort is presented, it is not obvious whether functional task behavior is caused by an internal and unstable ascription or by the perception of personal control.

Explicit causes such as lack of effort may thus yield unforeseen interpretation processes that cannot be controlled by the researcher. A manipulation of locus of causality and stability without using explicit causes creates the possibility to study the effects of locus of causality and stability on behavior without unforeseen influences of interpretational processes such as the perception of control. To our knowledge, this is one of the first studies that investigates causal ascription (locus of causality and stability) separately from unforeseen influence of the highly interrelated yet distinct causal dimension of control.

By manipulating causal ascriptions (e.g., internal and unstable) without affecting causal interpretation following from those assigned causes (e.g., perceived control) the separate effects of causal ascription after error occurrence on functional task behavior can be tested. We propose that causal ascriptions influence functional task behavior through the causal interpretation process. We will also report findings on the partition of the attribution mechanism into a causal ascription and a causal interpretation component. In the following section the concepts of causal ascription and causal interpretation will be further developed.

\section{Causal Ascriptions and the Process of Interpretation}

We consider causal ascription as a core causal characteristic which by itself does not convey meaning. After core causal characteristics of the error have been identified (e.g., internal and unstable), meaning can be construed by the process of interpretation, which, we propose, in turn influences subsequent behavior.

We argue that the interpretational process after error occurrence consists of interpretations related to personal control and responsibility. As discussed earlier, control has a strong influence on behavior, but there has been quite some debate about the incorporation of this dimension into the locus of causality and stability classification. We argue that in 
contrast to the causal dimensions stability and locus of causality, the amount of control implies interpretation of the situation whilst locus of causality and stability in essence are core causal characteristics, which in itself do not convey meaning.

The importance to study the separate effects of causal ascription (locus of causality and stability) and the interpretational process is further accentuated by research concerning perceived control. Research has shown that perceived control over negative outcomes has a large impact on behavior. Anderson and Arnoult (1985) demonstrated the superiority of control after failure over the other causal dimensions in predicting depression, loneliness and shyness. One of the first studies investigating the impact of control on negative outcomes were rat experiments of Mowrer and Viek (1948). Rats that were unable to control electrical shocks developed dysfunctional eating behaviors, whilst control rats eating behavior was not greatly affected. Hiroto and Seligman (1975) similarly demonstrated that people who perceive an inability to control outcomes perform poorer than people who perceive the ability to control outcomes. Similarly, Van Dyck (2005) found that making suggestions for improvement after error occurrence which were under control of the participant led to enhanced learning and performance. Thus, we propose that the degree of perceived control after error occurrence influences functional behavior.

We further propose that the interpretational process after error occurrence comprises, in addition to control, the degree of responsibility people perceive. In describing six areas of research; locus of control, personal causation, intrinsic-extrinsic motivation, perceived freedom, reactance and learned helplessness, Weiner (1980, p. 269) argued that these research areas "were all associated with the allocation of responsibility along an internal (self) vs. external (environmental) dimension." Responsibility can be denied by assigning outcomes to external causes, but can alternatively be acknowledged by attribution to either stable, or unstable internal causes (Tesser, 1988). Acknowledging responsibility is presumed to produce desirable behaviors such as openness to information and expectancy of success. Denying responsibility, in contrast, leads to undesirable behavior such as avoidance of information, lowered expectancy of success and lack of realism (Weiner, 1980).

We argue, therefore, that the core causal ascription can be classified by stability and locus of causality. From classified error causes, meaning can then be construed by the process of interpretation. This process of interpretation comprises perceived personal control and responsibility.

People do not automatically perceive control or acknowledge responsibility after errors. Before errors can be interpreted, the cause of the error has to be identified. Proposing that personal control and responsibility stem from the causal ascription of error (Hypotheses 2 and 
3 ), we further predict that the interpretational process mediates the relationship between the ascription of causes and functional task behavior.

Hypothesis 2: Internal unstable causal ascription of error leads to more personal control than the other types of causal ascription.

Hypothesis 3: Internal causal ascription of error leads to more responsibility than the other types of causal ascription.

Hypothesis 4: Personal control and responsibility mediate the relationship between the ascription of causes and functional task behavior.

\section{METHOD}

\section{Participants and Experimental Design}

One hundred twenty-five students participated in the experiment. ${ }^{1}$ The sample was composed of 84 (67\%) women and 41 men. Mean age was $20.77(S D=3.16)$. In return for their participation, they received seven Euros. Locus of causality (internal vs. external) and stability (stable vs. unstable) were manipulated in a $2 \times 2$ between subjects design. Participants were randomly assigned to one of the four experimental conditions.

Task

Participants were informed that during the experiment, tactical insight was investigated by playing three trials of a video game. A demo of Lemmings $^{\mathrm{TM}}$ developed by Kay (1991) was used for these three trials. Lemming $\mathrm{s}^{\mathrm{TM}}$ is a video game where the objective is to lead a group of lemmings from an entry point to an exit point. In order to advance to the next level, one has to save a certain percentage of lemmings. The video game is built up around different functions that can be used to develop strategies to lead the lemmings to an exit point. If, however, your strategy is wrong, the lemmings wander aimlessly into dangerous situations. When a level is successfully accomplished, an access code for entry to the next level is presented. Each level has its unique access code, consisting of 10 characters.

\footnotetext{
${ }^{1}$ Data from 15 individuals were excluded from further analyses. Thirteen participants successfully finished Trial 3, defying our error inducement of the task. Analyses revealed that the participants who accomplished the level within six minutes had far more experience in playing the game Lemmings ${ }^{\mathrm{TM}}(M=4.50)$ than the participants who had not accomplished Trial 3 ( $M=1.90 ; t$ (137) $6.85, p<.001$. One participant was unable to complete the experiment as the computer she was working on broke down and one participant erroneously claimed having finished Trial 3.
} 


\section{Functions}

The game can be played by using eight functions: climbing, floating, exploding, blocking, building, bashing, mining, and digging.

\section{Procedure}

Participants were seated in separate cubicles and were asked to follow the instructions provided on the computer screen. Participants were informed that during the experiment their tactical insight was investigated during three trials of the video game Lemmings ${ }^{\mathrm{TM}}$. The first screen on the computer welcomed the participants after which they were asked to complete a questionnaire. The questionnaire measured possible covariates. After filling in the questionnaire, participants played three trials of the video game. At the start of each trial participants received a manual and the manipulations were enforced.

The first manual informed participants about the objective of the game, game controls and information presented by the game. The purpose of Trial 1 was to familiarize the participants with the game. Trial 1 was completed when participants successfully played one level of the game while working through the manual of Trial 1. After participants finished Trial 1, the experimenter checked whether they had worked through the manual correctly. No time limit was set for Trial 1, so that participants could take their time to get familiar with the game.

During Trial 2, the participants were focused on the errors they made during the game and we let them take notice of the game's performance element. Before the start of Trial 2, the experimenter handed over the second manual and told the participants they could play for 10 minutes. Ten minutes was ample time for the participants to be confronted with errors and to accomplish several levels. Each time they made an error, participants were asked to pause the game and to write down a short error description in the manual. On average the participants wrote down 2.15 errors $(S D=1.17)$. The participants could check the time they had left, as an alarm was set.

Trial 3 introduced a level that contained an error inducement. At first sight, the level seemed attainable with a fairly easy strategy. However, there was only one efficient strategy to accomplish Trial 3. The participants were instructed to play the presented level for a maximum of 6 minutes. The experimenter gave the impression that it was possible to finish the more difficult third level by instructing the participants to call for the experimenter when they had accomplished Trial 3. As in Trial 2 , the participants could check the time they had left. The experimenter stopped the participants from working on the task when the alarm sounded. After being stopped from working on Trial 3, participants were asked to describe the strategies they had used during Trial 3, and were 
asked to fill out measures concerning causal attribution and their expectancy towards accomplishing Trial 3 if they would have another possibility to play Trial 3. After filling out the questions, the participants were debriefed, thanked and paid. The total duration of the experiment was 45-60 minutes.

\section{Manipulations}

The use of causal ascriptions (Stability $\times$ Locus of causality) was manipulated by instructing participants think about stable/unstable and internal/external causes when attributing their errors. As we were interested in the process of error cause interpretation, we made a distinction between the assignment of causal ascriptions and the subsequent process of interpretation. That is, we manipulated the causal ascriptions of Stability (stable vs. unstable) $\times$ Locus of causality (internal vs. external) and measured subsequent interpretations (see Measures section). In the next paragraph, the manipulations are illustrated by the internal stable condition. The other manipulations are specified within parentheses.

Before each trial we presented the text: "It is likely that you will make errors during this trial. Errors can be explained by a lot of different causes. During this trial, the purpose is to think of causes that are relatively stable [unstable] and related to you [the situation]. This means that the error is likely to [does not necessarily] occur again, and that the cause of error should be attributed internally [externally]". Thus, while explicit instructions were given to think about certain ascriptions, no actual examples of these ascriptions were offered.

In the manuals of Trial 1 and 2 the following text was presented: "Before starting this trial, we have asked you to think about possible causes for the errors you would make. Try to think of causes that are relatively stable [unstable] and relate to you [the situation]. What kind of causes of this type can you give for the errors you have listed?" In total, participants were reminded of the manipulation five times: before each of the three trials; and in the manuals of Trial 1 and 2.

\section{Measures}

\section{Control Variables}

To control for possible effects on the dependent variables, participants were asked to complete a demographic questionnaire concerning gender, age and education. Furthermore, a combination of two items was used to measure game proficiency. The two items were 'attitude towards video games' which was measured on a scale ranging from 1 (I really dislike playing video games) to 5 (I really like playing video games), and 
'amount of experience in playing the game Lemmings ${ }^{\mathrm{TM}}$ ' which was measured on a scale ranging from 1 (I have no experience at all in playing Lemmings $^{\mathrm{TM}}$ ) to 6 (I have a lot of experience in playing Lemmings ${ }^{\mathrm{TM}} ; k=2$, Cronbach alpha $=.56)$.

\section{Error Attribution}

To measure the dimensions (a) locus of causality; (b) stability and; (c) personal control, we used the corresponding items of the Causal Dimension Scale II (CDSII; McAuley, Duncan, \& Russell, 1992). The proposed attribution dimension $(d)$ responsibility was measured with a self-developed 3-item scale similar to those of the CDSII.

All items were measured on a 5-point scale. In this experiment we changed the root of each item "Is the cause something" as used in the CDSII (McAuley et al., 1992) to "Is the cause of the error something" (e.g., Is the cause of the error something you can regulate?).

The dimensions locus of causality $(k=3$, Cronbach alpha $=.71)$ and stability $(k=3$, Cronbach alpha $=.61)$ were used as a manipulation check. Personal control $(k=3$, Cronbach alpha $=.69)$ and responsibility $(k=3$; Cronbach alpha $=.79)$ are mediators in our theoretical model. The responsibility scale consists of the items: "Is the cause of the error something: (1) you hold yourself responsible for-you hold yourself not responsible for; (2) you are liable for-you are not liable for; and (3) that is accountable to you-not accountable to you."

\section{Functional Task Behavior}

Task behavior in Trial 3 was measured by (a) the perceived amount of expectancy of success after Trial 3; (b) the amount of exploratory behavior throughout Trial 3; (c) the efficiency of the proposed strategy after Trial 3; and (d) the quality of the proposed strategy after Trial 3.

\section{Expectancy of Success}

After Trial 3, participants were asked to estimate the total number of attempts they would need to accomplish Trial 3. The item was measured on a scale with 1 (I need one more attempt to accomplish Trial 3) and 9 (I need nine or more attempts to accomplish Trial 3) as anchor points. We reverse-scored the expectancy of success measure so that higher scores would indicate a higher expectancy of success.

\section{Exploratory Behavior}

Participants were asked to describe the strategies they had used while working on Trial 3. To arrive at a measure for exploratory behavior, each strategy was rated for functions. Exploratory behavior could thus range from 0 (no functions have been used) to 8 (all eight functions have been used). Two coders, blind to the experimental 
conditions, the first author and a graduate student, rated the strategies for the eight different functions (climbing, floating, exploding, blocking, building, bashing, mining, and digging). The graduate student was familiar with the game and the level played in Trial 3. The overall inter-rater agreement for the eight functions was sufficient (Cohen's kappa $=.78)$.

\section{Strategy}

After Trial 3, participants were asked to describe the strategy they would use if they had one more try. For Trial 3, the successful and most efficient strategy consisted of a combination of five functions (climbing, floating, blocking, digging and exploding). Each strategy was coded for these five functions. Strategy could thus range from 0 (no correct functions suggested) to 5 (five correct functions suggested) as anchor points. The overall inter-rater agreement was sufficient (Cohen's kappa $=.79$ ).

\section{Quality of Strategy}

The strategies that participants said they would use if they had one more try were all tested for quality (the percentage of saved lemmings). In the first step, the two coders independently of each other developed a classification for all described strategies. A comparison of the two classifications revealed that the two coders agreed on 10 strategies. Besides the 10 strategies they agreed on, one coder had identified two extra strategies. The two coders discussed these two strategies and agreed to put the two strategies into the strategy classification. ${ }^{2}$ In the second step, all 12 strategies were tested. Seven strategies led to a saving percentage of 0 . Two strategies led to a saving percentage of 33.4, one strategy led to a saving percentage of 90 , one strategy led to a saving percentage of 95 and one strategy led to a saving percentage of 98.5. The percentage of saved Lemmings associated with the strategy was used as our measure of quality of strategy.

\section{RESULTS}

\section{Manipulation Check}

The manipulations of the causal dimensions locus of causality and stability were successful. Participants that had been instructed to attribute errors to internal causes scored significantly higher $(M=3.18$,

\footnotetext{
${ }^{2}$ The two strategies the coders initially disagreed on were low quality strategies which one coder had placed under the strategy: no strategy. The two strategies were tested and did not lead to saved lemmings. The two taxonomies developed by the coders, thus do not lead to different results.
} 
$S D=1.00)$ on an internal locus of causality than participants that had been instructed to manipulate errors to external causes $(M=2.71$, $S D=.93 ; F(1,121)=6.07, p=.02)$. Participants that had been instructed to attribute errors to stable causes scored significantly higher $(M=2.68, S D=.85)$ on stability than participants that had been instructed to manipulate errors to unstable causes $(M=2.30, S D=1.00$; $F(1,121)=4.47, p=.04)$.

\section{Control Variables}

The majority $(67 \%)$ of our participants were female. Univariate Analyses of Variance (ANOVA) with gender included as a factor revealed that gender greatly affected personal control, responsibility and functional task behavior. Correlational analyses further showed that game proficiency was significantly correlated with expectancy of success $(r=.30, p<.01)$, exploratory behavior $(r=.33, p<.01)$, strategy $(r=.24$, $p<.01)$, and quality of strategy $(r=.33, p<.01)$. Gender was included as a factor in all analyses. Gender differences are reported whenever they reach conventional levels of significance. The control variable game proficiency was used as a covariate in all analyses. Partial correlations

Table 1

Means, Standard Deviations, Kappa's, and Partial Correlations between Causal Ascription (Manipulation Check), Causal Interpretation and Task Behavior with Gender and Game proficiency partialled out

\begin{tabular}{|c|c|c|c|c|c|c|c|c|c|c|c|}
\hline Variables & Scale & Kappa/ $\alpha$ & x $M$ & $S D$ & 1 & 2 & 3 & 4 & 5 & 6 & 7 \\
\hline \multicolumn{12}{|c|}{ Manipulation Checks } \\
\hline 1. Stability & $1-5$ & .61 & 2.47 & .92 & - & & & & & & \\
\hline $\begin{array}{l}\text { 2. Locus of } \\
\text { causality }\end{array}$ & $1-5$ & .71 & 2.92 & .98 & $.14-$ & - & & & & & \\
\hline \multicolumn{12}{|l|}{ Mediators } \\
\hline $\begin{array}{l}\text { 3. Personal } \\
\text { control }\end{array}$ & $1-5$ & .69 & 3.53 & .95 & -.15 & $.42^{* *}-$ & & & & & \\
\hline 4. Responsibility & $1-5$ & .79 & 3.06 & 1.04 & .13 & $.69 * *$ & $.63^{* *}$ & & & & \\
\hline \multicolumn{12}{|c|}{ Functional Task Behavior } \\
\hline $\begin{array}{l}\text { 5. Expectancy } \\
\text { of success }\end{array}$ & $1-9$ & n.a. & 6.09 & 2.50 & $-.21^{*}$ & .06 & $.23^{*}$ & $.23 *$ & - & & \\
\hline $\begin{array}{l}\text { 6. Exploratory } \\
\text { behavior }\end{array}$ & $0-8$ & .76 & 1.75 & 1.39 & -.14 & .14 & .16 & .12 & .09 & - & \\
\hline 7. Strategy & $0-5$ & .75 & .85 & 1.14 & -.16 & .12 & $.19 *$ & $.20 *$ & $.35^{* *}$ & $.35 * *$ & \\
\hline $\begin{array}{l}\text { 8. Quality } \\
\text { of strategy }\end{array}$ & $0-100$ & .79 & 17.23 & 30.54 & -.10 & .15 & $.21^{*}$ & $.24 * *$ & $.21^{*}$ & $.39 * *$ & $.62^{* *}-$ \\
\hline
\end{tabular}

Note. $N=125 ;$ n.a. $=$ not applicable $* p<.05 ; * * p<.01$, all tests are two-tailed. 
among the studied variables are displayed in Table 1 . The results do not differ substantially when the covariate Game proficiency is left out of the analyses.

\section{Hypotheses Testing}

\section{Effects of Causal Ascriptions on Functional Task Behavior}

A $2 \times 2$ (Locus of causality $\times$ Stability) multivariate analysis of variance (MANOVA) on expectancy of success, exploratory behavior, strategy and quality of strategy was performed to test Hypothesis 1 that internal unstable ascriptions lead to more functional task behavior than the other types of causal ascription styles.

The MANOVA revealed a significant univariate two-way interaction effect of Stability $\times$ Locus of causality on quality of strategy ( $F$ (1, $\left.122)=5.19 ; p<.05, \eta^{2}=.04\right)$. The nature of the two-way interaction is depicted in Figure 1. As predicted, internal unstable ascriptions led to a higher percentage of saved Lemmings than internal stable and external unstable ascriptions. Internal unstable ascriptions, however, did not lead to a higher percentage of saved Lemmings than external stable ascriptions.

Although there was a trend (see Table 2), internal unstable ascriptions did not lead to more exploratory behavior than the other types of causal ascriptions $(F(1,122)=1.95, n s)$. There was an unpredicted significant univariate main effect of locus of causality on exploratory behavior, $\left(F(1,122)=6.07, p<.05, \eta^{2}=.05\right)$. Participants that were instructed to attribute errors to internal causes showed more exploratory behavior $(M=2.03, S D=1.41)$ than participants instructed to attribute errors to external causes $(M=1.42, S D=1.35)$. The predictions that

\section{Figure 1}

Quality of Strategy as a Function of Locus of Causality and Stability (+1 en -1 Standard Deviations from the Mean)

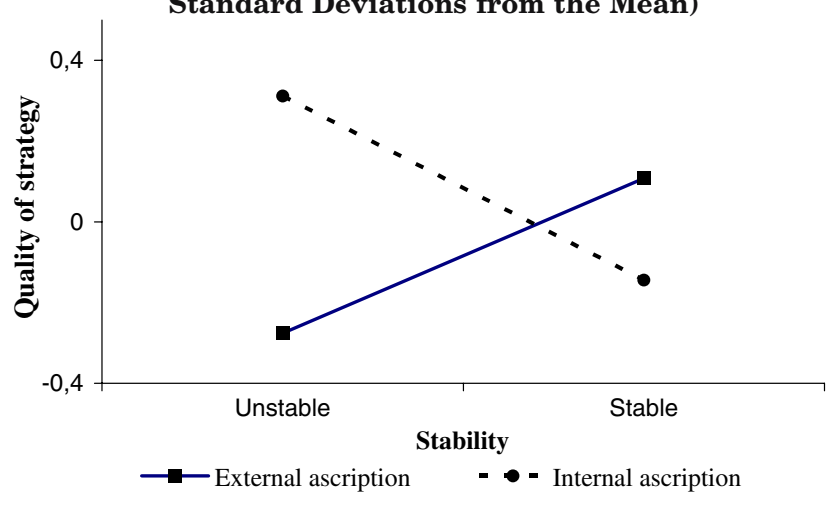


Table 2

Observed Means and Standard Deviations for Manipulation Check Variables, Causal Interpretation and Task Behavior with Gender included as a between persons-factor and Game proficiency included as a covariate

\begin{tabular}{|c|c|c|c|c|}
\hline & \multicolumn{4}{|c|}{ Experimental condition } \\
\hline & \multicolumn{2}{|c|}{ Internal } & \multicolumn{2}{|c|}{ External } \\
\hline & $\begin{array}{l}\text { Unstable } \\
M(S D)\end{array}$ & $\begin{array}{l}\text { Stable } \\
M(S D)\end{array}$ & $\begin{array}{l}\text { Unstable } \\
M(S D)\end{array}$ & $\begin{array}{c}\text { Stable } \\
M(S D)\end{array}$ \\
\hline $\begin{array}{l}\text { Sample } \\
\text { Manipulation check }\end{array}$ & $n=31$ & $n=29$ & $n=29$ & $n=36$ \\
\hline $\begin{array}{l}\text { Stability } \\
\text { Locus of causality } \\
\text { Mediators }\end{array}$ & $\begin{array}{l}2.37^{\mathrm{a}}(1.05) \\
3.22^{\mathrm{a}}(1.01)\end{array}$ & $\begin{array}{c}2.91^{\mathrm{b}}(.84) \\
3.13^{\mathrm{ab}}(1.00)\end{array}$ & $\begin{array}{l}2.22^{\mathrm{a}}(.94) \\
2.62^{\mathrm{b}}(.84)\end{array}$ & $\begin{array}{c}2.45^{\mathrm{ab}}(.82) \\
2.80^{\mathrm{ab}}(1.00)\end{array}$ \\
\hline $\begin{array}{l}\text { Personal control } \\
\text { Responsibility } \\
\text { Task behavior }\end{array}$ & $\begin{array}{c}3.83(.85) \\
3.36^{\mathrm{a}}(1.17)\end{array}$ & $\begin{array}{c}3.32(1.02) \\
3.13^{\mathrm{ab}}(1.10)\end{array}$ & $\begin{array}{l}3.34(1.12) \\
2.77^{\mathrm{b}}(.99)\end{array}$ & $\begin{array}{c}3.63(.83) \\
3.09^{\mathrm{ab}}(.92)\end{array}$ \\
\hline $\begin{array}{l}\text { Expectancy of success } \\
\text { Exploration } \\
\text { Strategy } \\
\text { Quality of strategy }\end{array}$ & $\begin{array}{c}6.00(2.47) \\
2.26^{\mathrm{a}}(1.41) \\
1.13(1.37) \\
26.45(35.03)\end{array}$ & $\begin{array}{c}5.89(2.56) \\
1.82^{\mathrm{ab}}(1.42) \\
.73(.92) \\
12.51(25.39)\end{array}$ & $\begin{array}{c}6.46(2.67) \\
1.29^{\mathrm{b}}(1.21) \\
.78(.86) \\
8.49(19.71)\end{array}$ & $\begin{array}{c}6.21(2.39) \\
1.54^{\mathrm{b}}(1.45) \\
.72(1.29) \\
20.20(36.03)\end{array}$ \\
\hline
\end{tabular}

Note. $N=125$, means in the same row that do not share a superscript differ at $p<.05$

internal unstable ascriptions lead to higher expectancy of success and better strategies than the other causal ascription styles were not supported. There were no interaction effects of Stability $\times$ Locus of causality on expectancy of success, $F(1,122)=.02$, $n s$, and strategy $(F(1$, $122)=.63, n s)$. Means and standard deviations are presented in Table 2.

\section{Effects of Causal Ascriptions on the Causal Interpretation Process}

In Hypothesis 2 we predicted that internal unstable ascriptions would lead to more personal control than would other types of causal ascriptions. An ANOVA on personal control revealed a two-way interaction of locus of causality and stability $(F(1,122)=4.74, p=.03$, $\left.\eta^{2}=.04\right)^{3}$. The nature of the two-way interaction is depicted in Figure 2.

${ }^{3}$ This effect was qualified by a significant Gender $\times$ Locus of causality $\times$ Stability interaction, $F(1,121)=5.91, p<.02$. Simple effects analyses revealed no overall differences in personal control between men and women, $F(1,123)=.01, n s)$ When we examined each sex differently, we found that the Locus of causality $\times$ Stability interaction was highly significant for men, $F(1,37)=7.22, p=.01$, but not for women, $F(1,81)=.04, n s$. Simple effects analyses revealed that men perceived more personal control when they ascribed errors to internal unstable and external stable causes than when they ascribed errors to internal stable and external unstable causes, $F(1,37)=7.22, p=.01$. 
Figure 2

Personal Control as a Function of Locus of Causality and Stability (+1 en -1 Standard Deviations from the Mean)

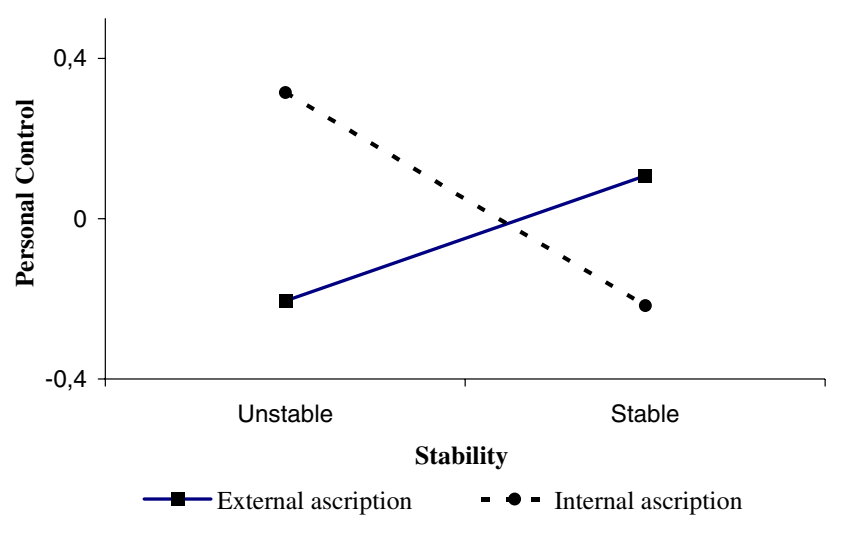

As predicted, internal unstable ascriptions led to more personal control than internal stable and external unstable ascriptions. Internal unstable ascriptions, however, did not lead to more personal control than external stable ascriptions. Hypothesis 2 was partially supported.

We further predicted that internal ascriptions would lead to more responsibility than external ascriptions (Hypothesis 3). ANOVA did not reveal a main effect of locus of causality on responsibility ( $F$ (1, $122)=2.44, n s)$. Hypothesis 3 was thus not supported. ${ }^{4}$

\section{Mediation Effects}

We predicted that both personal control and responsibility mediate the relationship between causal ascriptions and functional task behavior (Hypothesis 4). As Hypotheses 2 and 3 were respectively partially and not supported, no mediation effects of personal control and responsibility on the relationship between causal ascription and functional task behavior could be tested. Hypothesis 4 was not supported.

\section{Theoretical Distinction between the Causal Ascription and Causal} Interpretation Component

To assess whether our theoretical distinction between causal ascription and causal interpretation is supported by our data, we first

\footnotetext{
${ }^{4}$ There was a Gender $\times$ Locus of causality $\times$ Stability interaction, $F(1,121)=8.05$, $p<.01$. Simple effects analyses revealed no overall differences in responsibility between men and women, $F(1,123)=.28, n s$. When we examined each sex differently, we found that the Locus of causality $\times$ Stability interaction was again highly significant for men, $F$ ( 1 , $37)=6.66, p=.02$, but not for women, $F(1,81)=1.40, n s$. Simple effects analyses revealed that men perceived more responsibility when they ascribed errors to internal unstable than when they ascribed errors to the other types of causes; $F(1,37)=6.44, p=.02$.
} 
investigated the inter-correlations of the attribution variables. The partial correlation of the causal ascription variables stability with locus of causality (manipulation check) showed no significant relation. Stability did not have significant correlations with the causal interpretation variables. Locus of causality however, correlated positively with both personal control $(p r=.42, p<.01)$ and responsibility $(p r=.69, p<.01)$. The correlation of the causal interpretation variables personal control with responsibility was .63 $(p<.01)$. On the basis of the high relations between the causal interpretation process (personal control and responsibility) and locus of causality measures, the theoretical distinction between causal ascription and causal interpretation could be questioned.

To investigate our argument that locus of causality is indeed distinct from personal control and responsibility, we conducted confirmatory factor analyses. Confirmatory factor analyses were performed using LISREL 8.7 (Jöreskog \& Sörbom, 1993) on the items of the causal ascription and causal interpretation variables. Analyses of models that collapsed these factors together indicated that our proposed four-factor model provided a better fit to the data (see Table 3).

We tested our proposed four-factor model (stability, locus of causality, personal control, and responsibility) with logical combinations of the items into three-factor models and one two-factor model and found that the tested models fit the data less well than our proposed four-factor model proposed. First, a three-factor model of stability, responsibility and locus of causality and personal control combined fitted the data less well than the four-factor model proposed ( $\left.\chi_{\text {diff }}^{2} 28,53 ; p<.01\right)$. Second, a three-factor model of stability, locus of causality and personal control and responsibility combined also fitted the data less well than our proposed

Table 3

Model Fit for the Four-Factor Model and Four Alternative Models

\begin{tabular}{lccccccc}
\hline Model $^{\mathrm{a}}$ & $\chi^{2}$ & $\mathrm{df}$ & RMSEA & RMR & GFI & CFI & $\chi_{\text {diff }}^{2}{ }^{\text {a }}$ \\
\hline $\begin{array}{c}\text { Proposed four-factor model: stability, } \\
\text { locus of causality, personal control \& } \\
\text { responsibility }\end{array}$ & 62.17 & 48 & .05 & .11 & .92 & .98 & \\
$\begin{array}{c}\text { Three-factor model: responsibility } \\
\text { and locus of causality combined }\end{array}$ & 75.58 & 51 & .06 & .11 & .92 & .97 & $13,41^{*}$ \\
$\begin{array}{c}\text { Three-factor model: personal control } \\
\text { and responsibility combined }\end{array}$ & 89.69 & 51 & .08 & .12 & .89 & .95 & $27,52^{*}$ \\
$\begin{array}{c}\text { Three-factor model: locus of causality } \\
\text { and personal control combined }\end{array}$ & 90.70 & 51 & .09 & .13 & .88 & .95 & $28,53^{*}$ \\
$\begin{array}{c}\text { Two-factor model: locus of causality, } \\
\text { personal control and responsibility } \\
\text { combined }\end{array}$ & 98.40 & 53 & .09 & .13 & .87 & .95 & $36,23^{*}$ \\
\hline
\end{tabular}

Note. $N=125 ; * p<.01$; presents the difference in $\chi^{2}$ as compared to the proposed model. 
Table 4

Hierarchical Regression Analysis of Personal Control and Responsibility on Task Behavior

\begin{tabular}{|c|c|c|c|c|c|c|}
\hline & Predictor/step & $\beta$ & $R^{2}$ & $F_{R^{2}}$ & $\Delta R^{2}$ & $F_{\Delta R^{2}}$ \\
\hline Step 1 & $\begin{array}{l}\text { Effects on Expectancy of Success } \\
\text { Game proficiency } \\
\text { Gender } \\
\text { Locus of causality } \\
\text { Stability } \\
\text { Gender } \times \text { Locus of Causality } \\
\text { Gender } \times \text { Stability } \\
\text { Locus of causality } \times \text { Stability } \\
\text { Gender } \times \text { Locus } \times \text { Stability }\end{array}$ & $\begin{array}{c}.27^{* *} \\
-.06 \\
-.08 \\
.04 \\
.04 \\
.00 \\
-.01 \\
.05\end{array}$ & .11 & 1.7 & .11 & 1.70 \\
\hline Step 2 & $\begin{array}{l}\text { Personal Control } \\
\text { Responsibility }\end{array}$ & $\begin{array}{l}.13 \\
.16\end{array}$ & .17 & $2.28^{*}$ & .06 & $4.22 *$ \\
\hline Step 1 & $\begin{array}{l}\text { Effects on Exploratory Behavior } \\
\text { Game Proficiency } \\
\text { Gender } \\
\text { Locus of causality } \\
\text { Stability } \\
\text { Gender } \times \text { Locus of Causality } \\
\text { Gender } \times \text { Stability } \\
\text { Locus of causality } \times \text { Stability } \\
\text { Gender } \times \text { Locus } \times \text { Stability }\end{array}$ & $\begin{array}{l}.37^{* *} \\
.06 \\
.23^{*} \\
.03 \\
.02 \\
.00 \\
.13 \\
.17^{\#}\end{array}$ & .19 & $3.41^{* *}$ & .19 & $3.41^{* *}$ \\
\hline Step 2 & $\begin{array}{l}\text { Personal Control } \\
\text { Responsibility }\end{array}$ & $\begin{array}{r}.12 \\
-.01\end{array}$ & .20 & $2.85^{* *}$ & .01 & .70 \\
\hline Step 1 & $\begin{array}{l}\text { Effects on Strategy } \\
\text { Game proficiency } \\
\text { Gender } \\
\text { Locus of causality } \\
\text { Stability } \\
\text { Gender } \times \text { Locus of Causality } \\
\text { Gender } \times \text { Stability } \\
\text { Locus of causality } \times \text { Stability } \\
\text { Gender } \times \text { Locus } \times \text { Stability }\end{array}$ & $\begin{array}{c}.26^{*} \\
.01 \\
.08 \\
.10 \\
.07 \\
-.02 \\
.08 \\
.08\end{array}$ & .09 & 1.49 & .09 & .49 \\
\hline Step 2 & $\begin{array}{l}\text { Personal Control } \\
\text { Responsibility }\end{array}$ & $\begin{array}{l}.07 \\
.15\end{array}$ & .13 & $1.73^{\#}$ & .04 & $2.50^{\#}$ \\
\hline Step 1 & $\begin{array}{l}\text { Effects on Quality of Strategy } \\
\text { Game Proficiency } \\
\text { Gender } \\
\text { Locus of causality } \\
\text { Stability } \\
\text { Gender } \times \text { Locus of Causality } \\
\text { Gender } \times \text { Stability } \\
\text { Locus of causality } \times \text { Stability } \\
\text { Gender } \times \text { Locus } \times \text { Stability }\end{array}$ & $\begin{array}{c}.31^{* *} \\
-.01 \\
.08 \\
.02 \\
.05 \\
-.04 \\
.21^{*} \\
.15\end{array}$ & .17 & $2.86^{* *}$ & .17 & $2.86^{* *}$ \\
\hline Step 2 & $\begin{array}{l}\text { Personal Control } \\
\text { Responsibility }\end{array}$ & $\begin{array}{l}.04 \\
.18\end{array}$ & .20 & $2.91 * *$ & .03 & $2.77^{\#}$ \\
\hline
\end{tabular}

Note. $N=125,{ }^{*} p<.10,{ }^{*} p<.05, * * p<.01$, all tests are two-tailed. 
four-factor model ( $\chi_{\text {diff }}^{2} 27,52 ; p<.01$ ). Third, a three-factor model of stability, personal control and locus of causality and responsibility combined also fitted the data less well than the four-factor model proposed ( $\chi_{\text {diff }}^{2}$ $13,43 ; p<.01)$. We also tested a two-factor model with stability as a separate factor and locus of causality, personal control and responsibility as a combined factor. Finally, we tested the two-factor model and found it to fit the data less well than the four-factor model proposed ( $\chi_{\text {diff }}^{2} 36,23$; $p<.01$ ).

To further explore this issue, we conducted standardized hierarchical regression analyses (see Table 4). This was done so that we could test whether causal interpretation variables had effects on functional task behavior above and beyond causal ascriptions. After controlling for the full-factorial model of the variables gender, locus of causality and stability and the covariate game proficiency (Step 1), we put the variables personal control and responsibility into the second step of the analyses. We found that the second step of the analyses containing the causal interpretation variables personal control and responsibility still explained extra variance on expectancy of success, strategy and quality of strategy. As reported in Table 4, the causal interpretation process explains an additional six percent of the variance in the dependent variable expectancy of success $\left(F_{\Delta R^{2}}=4.22, p<.05\right)$, whereas step $1 \mathrm{did}$ not reveal a significant effect $\left(F_{\Delta R^{2}}=.82, n s\right)$. Higher personal control and responsibility lead to a higher expectancy of success. The causal interpretation process explains furthermore an additional four percent of variance in strategy and quality of strategy $\left(F_{\Delta R^{2}}=2.50, p<.10\right.$ and $\left.F_{\Delta R^{2}}=2.77, p<.10\right)$, respectively.

To summarize, although causal ascriptions and causal interpretations are highly correlated, they affect task behavior differently. Based on confirmatory factor analyses, we can conclude that the four factors represent empirically distinct constructs. Standardized hierarchical regression analyses further showed that the causal interpretation process is a valuable predictor of expectancy of success, strategy and quality of strategy above and beyond the causal ascription process. Standardized regression analyses on quality of strategy revealed the earlier described interaction effect of stability and locus of causality. Internal unstable and external stable ascriptions lead to higher quality strategies than internal stable and external unstable ascriptions. Personal control and responsibility did not affect exploratory behavior.

\section{DISCUSSION}

The goal of our study was two-fold. As every organization has to deal with errors, it is essential to generate more knowledge about the ante- 
cedents of behavior after error occurrence. The causal attribution mechanism has been identified as an important antecedent of behavior. Our main objective was, therefore, to establish the influence of attribution after error occurrence on subsequent task behavior. As recent research has shown that the same explicit cause can lead to a variety of causal ascriptions (Van Dyck \& Homsma, 2005), we decided not to use explicit causes for the manipulation of causal ascription.

By manipulating causal ascription, rather than using explicit causes we were able to extend the understanding of the causal attribution mechanism. The manipulation of causal ascription without explicit causes made it possible to study the effects of causal ascription (locus of causality and stability) without interference of the causal interpretation process (personal control and responsibility). Unlike studies using explicit causes for the manipulation of causal ascription, we were thus able to describe the pure relation between causal ascription, causal interpretation and functional task behavior.

In line with research on failure attribution (Abramson et al., 1978; Bandura, 1982; Weiner, 1985), our results revealed a trend that participants instructed to think about internal and unstable causes after error occurrence, carried out more exploratory behavior than those instructed to use other causal ascriptions. Internal unstable ascriptions after error occurrence also led to higher quality strategies than did internal stable and external unstable ascriptions. Looking at quality of strategy, however, participants instructed to assign errors to external stable causes did equally well as participants instructed to assign errors to internal unstable causes. This result could be explained by what Seligman and Schulman (1986) have described as the optimistic explanatory style for bad events. They found that in situations where people repeatedly encounter failure, rejection and indifference, external failure attributions predict survival and productivity. Since video games as Lemmings are developed to entertain people through challenging levels, the game could be perceived as a situation in which errors regularly occur. Contrary to our expectation, internal unstable ascriptions did not lead to better strategies and expectancy of success than the other ascriptions. The fact that the superiority of internal unstable ascriptions over the other ascriptions was only partially supported, could be explained by the separation of the error attribution mechanism into a causal ascription and a causal interpretation component. The manipulation of causal ascriptions free of confound with the causal interpretation process did reveal different relations with functional task behavior when compared with research using explicit causes for ascriptions. Significant relations of personal control and responsibility with expectancy of success, strategy and quality of strategy offer room for the suggestion that not causal ascriptions but causal interpretations predict behavior. These results 
suggest that instead of causal ascriptions, the causal interpretation process might have a stronger influence on behavior after setbacks.

The current study started with the notion that the influence of causal ascriptions on functional task behavior runs through the process of causal interpretation. Due to the fact that we found that internal unstable and external stable ascriptions lead to higher quality strategies than external unstable and internal stable ascriptions, we were unable to confirm the hypothesis of the causal interpretation process as a mediator.

With regard to our test of effects of causal interpretation after causal ascriptions have been accounted for, the causal interpretation process seems to be a valuable predictor of expectancy of success, strategy and quality of strategy. We found significant relations between causal interpretation and functional task behavior. Personal control and responsibility both related positively with expectancy of success, strategy and quality of strategy. In contrast to the causal interpretation process, causal ascriptions were not significantly correlated with expectancy of success and strategy. This is an interesting finding, as it emphasizes the importance of separating the error attribution mechanism into a causal ascription and a causal interpretation component.

Although substantial correlations were found between the factors locus of causality, personal control and responsibility, analyses of models that collapsed these factors together indicated that our proposed fourfactor model provided a better fit to the data. The high correlation between responsibility and personal control is a point of concern as it questions the necessity to include both variables in the interpretational process. Although the correlation between responsibility and personal control is indeed a point of concern, we think that it is too early to draw conclusions. The setting in which errors take place, for example, might influence the relation between personal control and responsibility. Although personal control and responsibility will always be related to each other it is likely that acknowledgement of personal control and responsibility will differ under other circumstances. The current experimental setting, for example, was individualistic in nature as there were no other individuals present who could take responsibility for the errors. Responsibility might play a different role in organizational settings. Supervisors for example are likely to perceive differences in acknowledged responsibility when their subordinates do not meet deadlines. Independent of high or low personal control, the supervisor can acknowledge a lot of responsibility (e.g., "I should have been on the spot instead of attending the board-meeting"). On the other hand, the supervisor can acknowledge little responsibility (e.g., "whenever I have other obligations, they work careless").

In summary, results of our study suggest that internal unstable ascriptions and external stable ascriptions are superior to internal stable 
and external unstable ascriptions. That is, with regard to personal control and quality of strategy. This outcome contradicts the dominant stream of research, which states that internal unstable ascriptions are superior to the other types of ascriptions. The manipulation of causal ascriptions free of confound of causal interpretation might be accountable for this finding. Future research should reveal whether causal interpretation processes affect subsequent behavior above and beyond causal ascriptions. Our results suggest that indeed causal ascription and interpretation have distinct relationships with functional task behavior. We think that future research that looks into the precise working of the attributional mechanism by manipulating causal ascriptions without influencing causal interpretation can have great potential to lead to a more profound understanding of the relationship between error attribution and subsequent behavior.

\section{Strengths and Limitations}

The strength of the experiment lies in the separation of the error attribution mechanism into a causal ascription and a causal interpretation component. To our knowledge, this is the first time that causal ascriptions have been experimentally manipulated in a pure sense, without confound of the causal interpretation process.

Although it turned out that the manipulation check was successful, the effect of the stability manipulation was quite small. We cannot be sure whether this can be ascribed to the manipulation itself or to difficulties in manipulating certain causal ascriptions. The setting of the experiment may have caused the small effect of the stability manipulation. It is possible that the video game used for the experiment was not suitable for making external ascriptions as video games in essence can be mastered by practice. Although we acknowledge this possibility, we have reason to believe that the experiment was set up in such a way that it provided sufficient opportunities to attribute errors to external causes. First, the manipulation check measure showed a symmetric distribution on our locus of causality measure. Second, investigation of the participants' written error causes revealed six categories that could be depicted as external causes. The participants attributed errors to the four common external causes (1) time pressure; (2) task difficulty; (3) bad luck; (4) noisy conditions. The participants furthermore blamed (5) the lemmings; and (6) the instructions.

When experiments are built up around a task, one should control for gender specificity. In our experiment, we did find gender differences for personal control and responsibility. Gender specificity, however, can influence any type of study investigating causal attribution. Causal attribution studies have regularly reported the influence of gender on 
causal attribution (e.g., Mitchell, 1987; Ryckman \& Peckham, 1986; Valas, 2001). The gender differences in this study, revealed a consistent pattern. When we examined men and women separately, we found no differences for women in the different types of ascriptions. Men perceived more personal control and responsibility when they ascribed errors to internal unstable and external stable ascriptions than when they ascribed errors to internal stable and external unstable causes. As tasks in fact always run the risk of being gender specific, future research on the attributional mechanism should consistently incorporate gender as a factor in the analyses.

\section{Practical Implications}

As making errors is human, organizations have to deal with the errors made by their employees. The aim of organizations is often to prevent errors from occurring in the first place (Argyris, 1992). However, an organizational strategy exclusively aimed at error prevention has its limitations, as it is impossible to eliminate error occurrence (Reason, 1997). It has been documented that constructive error handling is positively related to performance (Edmondson, 1996; Van Dyck, Frese, Baer, \& Sonnentag, 2005). Furthermore, error-handling patterns after error occurrence are shared by employees within organizations (Van Dyck, 2000). Although we know that behavior after error occurrence is associated with performance and task behavior (Van Dyck, 2005), so far, little is known on how those behaviors originate. Our study has tried to provide more insight in the error attribution mechanism after error occurrence.

We believe that the separation of the error attribution mechanism after error occurrence into a causal ascription and a causal interpretation component is an interesting framework which has considerable potential to lead to a more thorough understanding of behavior after error occurrence. From a practical perspective, the separation of the error attribution mechanism into a causal ascription and a causal interpretation component might offer interesting implications for organizations to encourage their employees to ascribe and interpret error causes constructively.

As error handling is related to performance, managers should invest effort in the promotion of functional task behavior after error occurrence. One tool for managers to take hold of the subordinates' behavior after error occurrence is their interpretation process after error occurrence. Managers should focus on creating an atmosphere in which employees consistently take responsibility and find ways to perceive control after error occurrence. As the creation of shared understanding is a difficult and time-consuming activity, managers should try to set an example for 
the subordinates. By consistently taking responsibility for errors and finding ways to perceive control over errors, subordinates should eventually develop a shared functional understanding on how to interpret errors and to constructively deal with them.

\section{REFERENCES}

Abramson, L. Y., Seligman, M. E. P. \& Teasdale, J. D. (1978). Learned helplessness in humans: Critique and reformulation. Journal of Abnormal Psychology, 87, 49-74.

Anderson, C. A. (1983). Motivational and performance deficits in interpersonal settings: The effect of attributional style. Journal of Personality and Social Psychology, 45, 11361147.

Anderson, C. A. \& Arnoult, L. H. (1985). Attributional style and everyday problems in living: Depression, loneliness, and shyness. Social Cognition, 3, 16-35.

Argyris, C. (1992). On organizational learning. Oxford: Blackwell.

Bandura, A. (1977). Self-efficacy: Toward a unifying theory of behavioral change. Psychological Review, 84, 191-215.

Bandura, A. (1982). Self-efficacy mechanism in human agency. American Psychologist, 37, 122-147.

Chapin, M. \& Dyck, D. G. (1976). Persistence in children's reading behavior as a function of $\mathrm{N}$ length and attribution retraining. Journal of Abnormal Psychology, 85, 511-515.

Chillarege, K. A., Nordstrom, C. R., \& Williams, K. B. (2003). Learning from our mistakes: Error management training for mature learners. Journal of Business and Psychology, 17, 369-385.

De La Rochefoucauld, F. (1815). Maximes and réflexions morales [maxims and moral reflections]. Paris: Didot.

Dweck, C. S. (1975). Role of expectations and attributions in alleviation of learned helplessness. Journal of Personality and Social Psychology, 31, 674-685.

Edmondson, A. (1996). Learning from mistakes is easier said than done: Group and organizational influences on the detection and correction of human error. Journal of Applied Behavioral Science, 32, 163-187.

Försterling, F. (1985). Attributional retraining: A review. Psychological Bulletin, 98, 495512.

Fowler, J. W. \& Peterson, P. L. (1981). Increasing reading persistence and altering attributional style of learned helpless children. Journal of Educational Psychology, 73, 251260.

Heider, F. (1958). The psychology of interpersonal relations. New York: Wiley.

Heimbeck, D., Frese, M., Sonnentag, S., \& Keith, N. (2003). Integrating errors into the training process: The function of error management instructions and the role of goal orientation. Personnel Psychology, 56, 333-361.

Hewstone, M., \& Antaki, C. (1988). Attribution theory and social explanations. In M. Hewstone, W. Stroebe, J. P. Codol, \& G. M. Stephenson (Eds.), Introduction to social psychology: A European perspective (pp. 111-141). Oxford: Blackwell.

Hiroto, D. S. \& Seligman, M. E. (1975). Generality of learned helplessness in man. Journal of Personality and Social Psychology, 31, 311-327.

Jöreskog, K. \& Sörbom, D. (1993). LISREL 8: Structural equation modeling with the SIMPLIS command language. Chicago: Scientific Software International.

Kay, R. (1991). Lemmings ${ }^{\mathrm{TM}}$ (Demo version) [Computer Software]. Foster City, CA: Psygnosis.

Kelley, H. H. (1971). Attributions in social interactions. Morristown, NJ: General Learning Press.

Maier, S. F. \& Seligman, M. E. P. (1976). Learned helplessness: Theory and evidence. Journal of Experimental Psychology, 105, 3-46. 
McAuley, E., Duncan, T. E., \& Russell, D. W. (1992). Measuring causal attributions: The revised causal dimension scale (CDSII). Personality and Social Psychology Bulletin, 18, $566-573$.

Medway, F. J. \& Venino, G. R. (1982). The effects of effort feedback and performance patterns on childrens attributions and task persistence. Contemporary Educational Psychology, 7, 26-34.

Mitchell, C. L. (1987). Relationship of feminity, masculinity, and gender to attribution of responsibility. Sex Roles, 16, 151-163.

Mowrer, O. H. \& Viek, P. (1948). An experimental analogue of fear from a sense of helplessness. Journal of Abnormal and Social Psychology, 43, 193-200.

Nordstrom, C. R., Wendland, D., \& Williams, K. B. (1998). "To err is human": An examination of the effectiveness of error management training. Journal of Business and Psychology, 12, 269-282.

Reason, J. (1997). Managing the risks of organizational accidents. Hampshire, U.K: Ashgate.

Rosenbaum, R. M. (1972). A dimensional analysis of the perceived causes of success and failure (Doctoral dissertation, University of California, 1972). Dissertation Abstracts International, 33, 5040 .

Ryckman, D. B. \& Peckham, P. D. (1986). Gender differences on attribution patterns in academic areas for learning disabled students. Learning Disabilities Research, 1, 8389.

Schunk, D. H. (1981). Modeling and attributional effects on children's achievement: A selfefficacy analysis. Journal of Educational Psychology, 73, 93-105.

Seligman, M. E. P. \& Schulman, P. (1986). Explanatory style as a predictor of productivity and quitting among life insurance sales agents. Journal of Personality and Social Psychology, 50, 832-838.

Tesser A. (1988). Towards a self-evaluation maintenance model of social behavior. In L. Berkowitz (Ed.), Advances in experimental social psychology (Vol. 21). San Diego: Academic.

Valas, H. (2001). Learned helplessness and psychological adjustment: Effects of age, gender and academic achievement. Scandinavian Journal of Educational Research, 45, 71-90.

Van Dyck, C. (2000). Putting errors to good use: Error management culture in organizations. Doctoral dissertation, KLI dissertation series. Amsterdam: University of Amsterdam.

Van Dyck, C., Frese, M., Baer, M., \& Sonnentag, S. (2005). Organizational error management culture and its impact on performance: A two-study replication. Journal of Applied Psychology, 90, 1228-1240.

Van Dyck, C. (2007). Error approach and reinforcement effects disentangled: Confounds of the field tested in the lab. Manuscript in preparation.

Van Dyck, C., \& Homsma, G. J. (2005). "Yes, it's my fault, but I couldn't help it." How acknowledging control and responsibility can be just one bridge too far. In G. Zaccardi (Ed.), Quaderni di psicologia del lavoro (Vol. 12, pp. 119-125). Milan, Italy: Guerini Studio.

Weiner, B. (1980). Human motivation. New York: Holt, Rinehart and Winston.

Weiner, B. (1985). An attributional theory of achievement motivation and emotion. Psychological Review, 92, 548-573.

Weiner, B. (1986). An attributional theory of motivation and emotion. New York: SpringerVerlag.

Weiner, B., Frieze, I. H., Kukla, A., Reed, L., Rest, S., \& Rosenbaum, R. M. (1971). Perceiving the causes of success and failure. Morristown, NJ: General Learning Press. 